\title{
CONDITION MONITORING OF LUBRICATING OIL USING INTERNET OF THINGS (IoT)
}

\author{
KESHAV KUMAR JHA, RAHUL ARORA \& B.S PABLA
}

Department of Mechanical Engineering, NITTTR, Chandigarh

\begin{abstract}
Internet of Things (IoT) in the Industrial field is in big demand it meets several real-life applications like smart transportation, smart machine to make life more reliable. With the evaluation of industrialization in the field of IoT, an excessive number of various sensing data is producing with the help of various sensory devices in Industrial IoT. Nowadays we talk about Industry 4.0, smart industry, smart machine real-time monitoring of the automobile system is so crucial for the life of the machine. Internet of Things (IoT) is one of the smart communicating ways that create a strong impact on the future of the automobile industry and with the rising value of using the Internet of thing the needs of human physical work being reduced. One such application is real-time monitoring of lubricating engine oil, as the people still use the conventional way of checking the engine oil quality or level of engine oil degradation by physical means only. In this paper we make a smart sensing model detect the oil heath monitoring (OHM) to save the life of various parts of the engine machine. IoT based network systems can be developed to know the exact condition of engine oil on your phone with the help of various sensors. OHM system based on various parameters like viscosity, temperature, other constituent particles present in the engine oil, types of engine, the model of engine, also on the driving condition, driving area (dirt/unpaved roads), etc.
\end{abstract}

KEYWORDS: IoT Network System, Oil Heath Monitoring (OHM) System, Smart Sensor, Real-Time Monitoring

Received: Jun 08, 2020; Accepted: Jun 28, 2020; Published: Aug 29, 2020; Paper Id.: IJMPERDJUN2020943

\section{INTRODUCTION}

With the advancement of technology in the automobile industry sector, it gives the safest and comfortable to the vehicle user (Make introduction like Cathy). The emerging technology in the automobile industry our vehicles becomes smart with the use of various smart sensors connectivity, improve the efficiency of fuel, mapping technology, and many other features. The various innovations by many big companies in this sector bring an autonomous car that changes the industry and change the world. One innovation that can be implemented in any machine to increase the efficiency and life of the engine is oil health monitoring to predict the life of engine oil in real-time for this IoT based network can be developed that comprises the use of the various sensor. The properties of the oil, like its viscosity changes with running time of machine also the thinning of oil because of low viscosity and thickening of oil due to high viscosity. With the increase of temperature the viscosity decreases that can be measure in terms of the viscosity index and various instruments used to measure the viscosity of oil in the lab, many of viscometer are the portable type that can be used easily but the cost is too high that increase the cost of the vehicle [1]. Other properties based on $\mathrm{pH}$, acidic concentration, and alkaline concentration present in engine oil when the lubricating oil breaks down, and the wear particle monitoring consist of a ferrography technique that is based on the conductivity of oil debris[2] [3][6]. The oil heath condition in real-time is one of the major issues in this modern automobile industry due to a lack of automation technology in this area of finding the exact condition 
of engine oil. So in this research, we work on the design and the development of a cost-effective IoT based model system for finding the oil degradation, oil depth also the temperature of the oil in a continuous running engine. This paper includes an OHM system that used for finding the real-time oil conditioning using IoT network and other contribution that is given as follows:

- Design a working model for OHM system for monitoring the visibility of lubricant in real-time, level and temperature of oil, etc. with the use of IoT network interfacing various sensors.

- LED-LDR, LM 35 temperature, and Ultrasonic sensors are deployed in the path of oil flow for monitoring the lubricant health and its condition during the period.

- To testify the designed OHM model, we find the value of Quality of Oil (PPM) concerning the covered distance travel by Scooter.

The Implementation procedure for the developed OHM system for monitoring engine oil with the use of IoT network is discussed in Section 1 of the research article \& the other remaining research article is organized in Section 2 , the survey of the existing related works and in Section 3 the structure of OHM system is discussed. In Section 4, the experimental results and analysis are discussed. The last part of the section describes the conclusion and future scope.

The structure of the Oil Heath Monitoring system consists of three phases i) Data Sensing from sensor ii) Transmission based on IoT iii) Oil Monitoring. These various phases are illustrated in fig. 1

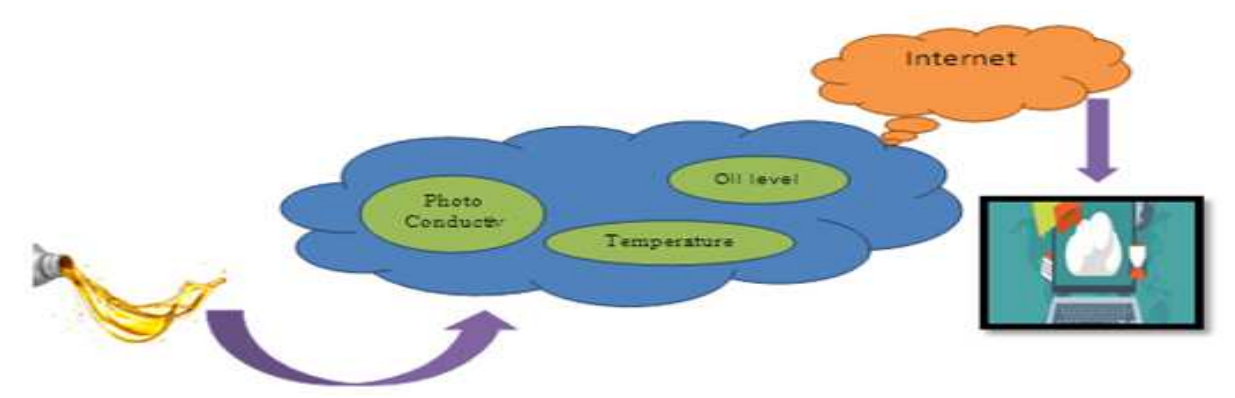

Figure 1: Structure of IoT Based OHM System.

\section{BACKGROUND SURVEY}

The brief review by the various researchers on the existing work related to oil condition monitoring is classified on various approaches like Oil physical and chemical properties, a viscosity of the oil, turbidity, acid number, or base number of oil with the use of the various sensors. Zhu et.al [5] described oil health monitoring, diagnostic, and prognostics. There a comprehensive review of available lubrication oil conditioning techniques is analyzed and categorized into four parts such as electrical, physical, chemical, and optical. The sensing technique and characteristics of each solution are evaluated with properties and there is a comparison between them. Various oil condition monitoring sensing techniques for various performance parameters like TAN/TBN, water content, wear particle count, flash point, viscosity, etc., are studied. Sejkorová et.al [6] introduced FTIR spectrometry as well as the analytic ferrography method for used engine oil using a high spectral resolution of data over the wide range and the ferrography is related to the tribology concept used to study the wear particles in the oil. Sample taken is motor oil used in ZETOR tractors and this sample oil exposed to various loading during autumn tasks and the friction process in motor affected which results in increased wear. Oil physical and chemical state evaluated by FTIR spectrometry Jakobe et.al [7] proposed the technique to find out the viscosity of 
lubricating oil using micro acoustic viscosity sensor and measuring the viscosity of various engine oil of cars and fresh oil samples. Viscosity dependence on temperature and other material in the lubricating oil samples. Viscosity increases due to the soot contamination in the oil. The sensor is based on the vibration of the probe of the sensor and gets the oscillation waves curve from there the viscosity value be demonstrated. Onboard, automotive lubricants conditioning by given viscosity sensor from $40{ }^{\circ} \mathrm{C}$ to $150{ }^{\circ} \mathrm{C}$ will be evaluated with a graph. Shinde et.al [1] measured the deterioration of engine oil in terms of viscosity, transmittance, and conductivity using the various sensors. For finding the useful remaining life of the engine oil which are underuse are detected using various important factors like viscosity and conductivity. In this research a selected engine oil used (SAE 15W40) for the light motor vehicle are used and reading with various kilometer it travels are noted and after the various analysis of engine oil it measures and analysis is done [43]. Mandekar et al [8] In this article they developed a model based on IoT in which it monitors the distribution of transformer oil earlier it monitors by manual. Multiple parameters like oil level, temperature, current, voltage, the viscosity of transformer oil are monitoring at real-time with the sensor and in this system temperature and viscosity monitoring based on AVR microcontroller and with interfacing the required component the user develop application program on embedded $\mathrm{c}$ in which controller continuously reading the above parameter and display at LCD. The result of this thesis is based on the IoT platform, if any changes in the predefined set of data there is signal via message or the internet. Koranga [9] with the use of the Internet of things (IoT) the researcher developed and designed IoT based platform with the software and hardware interface for condition monitoring using vibration analysis of machine. This thesis deals with interoperability between machine, sensor, and actuator and also adding features such as cloud storage and analytics. The sensor chosen was an accelerometer with large bandwidth and design for machine health monitoring. Agoston et.al [10] used micro acoustic sensors for investigating the data for the viscosity of engine oil. The sensor probe used has a distinct rheological domain that considers in the measurement of the result. Measuring the viscosity in the presence or absence of additives in engine oil is like that of the artificial aging method. The sensing device in this is a thin piezoelectric type quartz disk that excited electrically by a thin conditioning electrode present on both sides of the disk. The micro acoustic type viscosity sensor uses Thickness Shear Mode (TSM) of the micro acoustic quartz-based resonator that contains a resonating frequency of $6 \mathrm{MHz}$ which have $4 \mathrm{~mm}$ electrode and $8 \mathrm{~mm}$ of the disk diameter, which was fully immersed in the samples such that both the disk faces are in the close contact with the oil lubricants.

After the analysis of various existing researches and work by the researcher, we concluded some useful points regarding the development Oil Health Monitoring (OHM) system that helps for shorting out the existing problem of the engine oil condition monitoring system. In this existing work some of the major problems are [5-23].

- Difficult to decide, whether the engine oil quality level degraded

- $\quad$ Failed to decide the exact level or depth of engine oil in the sump of the engine

- Not able to decide the exact oil lubricant condition for maintaining their health status.

- $\quad$ Response time of the existing method based model, not up to an acceptable level.

For solving this type of existing problems, we introduce an OHM system in this particular research paper which can be presented in the following folds:

- Firstly, we study the various existing properties which are based on the oil condition monitoring process. 
- After that, we select the oil parameters such as viscosity, temperature; oil level, Photoconductivity, etc. with suitable sensors.

- For the data acquisition in this OHM system, we use a microcontroller with Arduino

- Data analysis and processing is done only after the acquisition of sensor data

- Assemble \& deploy the various coding in the microcontroller that helps to monitor the real-time condition of the oil

- To integrate the IoT system with the developed OHM system model to fetch the real-time data from the sensor also transmit it from one of the sources to another.

\section{STRUCTURE \& METHODOLOGY}

The methodology for this present research work based on online condition monitoring of engine oil is illustrated in flow chart 1 .

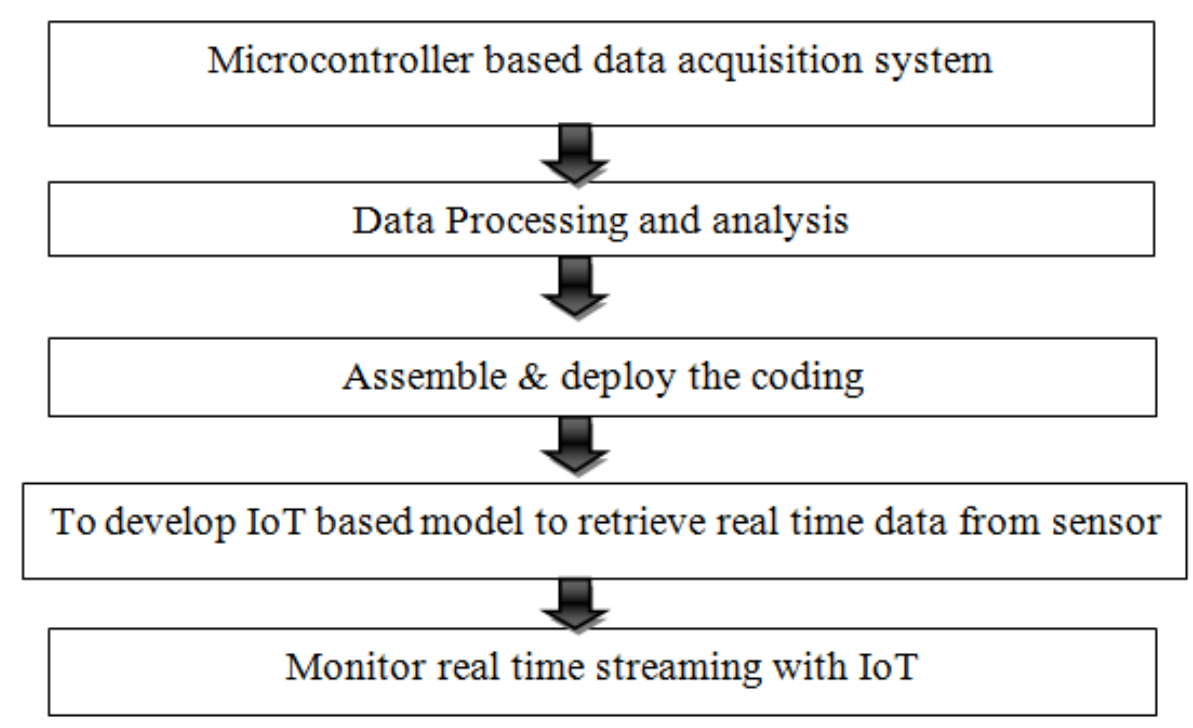

Flow Chart 1: Steps in Proposed Methodology.

\section{Microcontroller Based Data Acquisition System}

Various hardware systems are employed and integrate. The non-contact and contact type data retrieval system employed in the system is a novel integrated approach. During the processing of engine oil, real-time data will be collected through various sensors such as LED and LDR sensors [4], LM35 temperature sensors, and Ultrasonic oil level sensor. The Raw signal has been processed to extract the characteristic feature from the deployed sensor. The overall electronics setup is described in fig: 2 . 


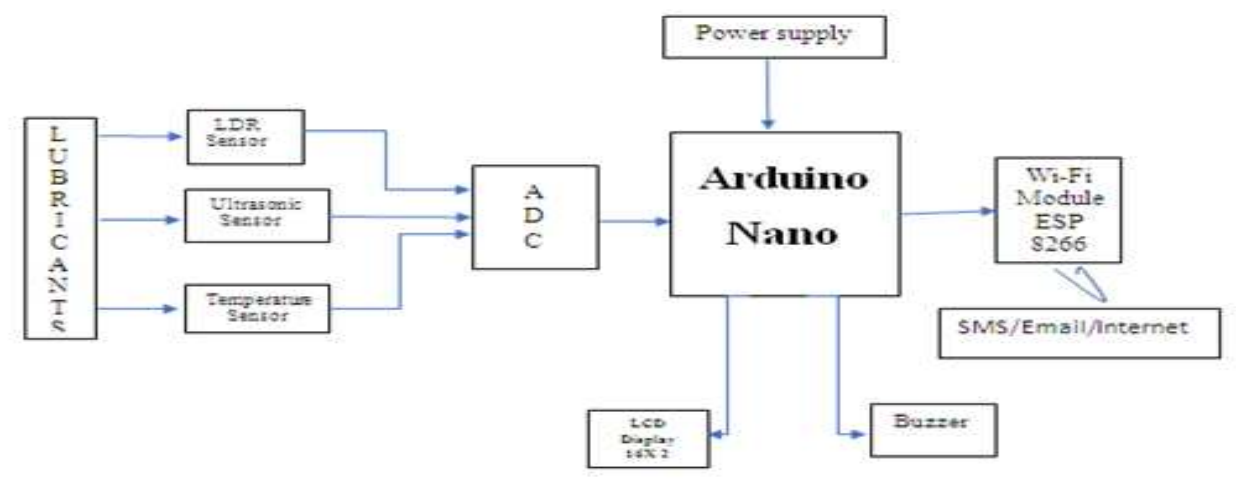

Figure 2: Block Diagram of Overall System Design.

\section{Data Processing and Analysis}

The programming is in Embedded C on Arduino, connecting the LDR, LM35, and Ultrasonic sensor to Arduino, the value coming from these sensors are check and analyses via Arduino. To do this, connect the Arduino via USB to the PC and open the Arduino IDE or software.

\section{Assemble and Deploy the Coding on the Microcontroller}

All hardware parts like sensors, controller, power supply, USB, PC, and Jumper wire are assembling with various predefined pins of Arduino, Nano microcontroller. The next part is to paste the programming code and upload it to Arduino. After uploading the generated code, click the button on the Arduino IDE called "Serial monitor". This will open a new window, which prints different values on the screen. Now, test out the various sensor and obtain the values on the Serial monitor.

\section{Software Used}

\section{A. Arduino IDE based Software}

Arduino IDE is integrated development based software that is present for the Arduino device which helps in coding to the Arduino microcontrollers for interfaces the sensors and also with another type of related components that perform the required operation, both on the local and global based domain from the help of given library functions.

\section{B. Matlab R2016a}

Matlab R2016a is recent which release from Mathworks and a new opportunity that offer the reliability for IoT projects and also the ThingSpeak is an IoT web service which offers the various data-based analysis on Matlab platform as an open-source with the full profile accesses through analyzing as per need of the given project and the implementation to the concerned areas like Various Industry, firms, research, hospitals, etc

\section{To Develop IoT Based Model to Retrieve Real-Time Data from the Sensor}

For IoT based system there use of Arduino controller interface with various sensors and the data obtain by these sensors are deployed by the program in $\mathrm{C}$ on Arduino, the Arduino connected to the Wi-Fi module through Thing speak which is open source Internet of Things application and API to store and retrieve the data from things using the HTTP protocol over the internet via Local Area Network. 


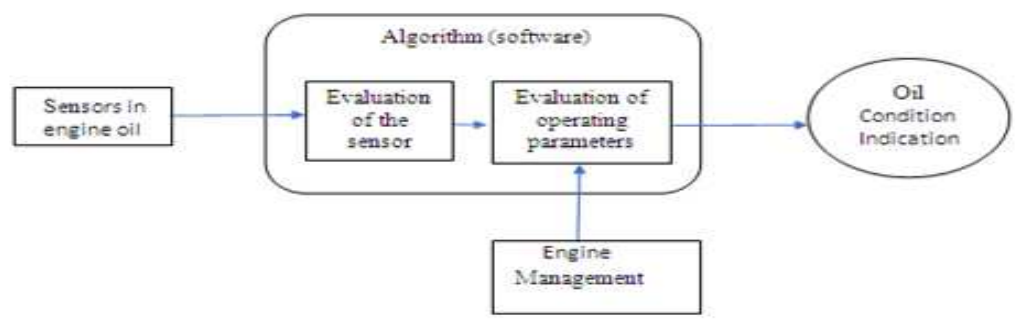

Figure 3: Structure of a Sensor Assisted Algorithm for a Lubrication Monitoring System.

\section{Monitor Real-Time Data Streaming using IoT}

To retrieve and monitor the real-time data from the sensor, the non-contact type sensor like LDR, Ultrasonic sensor, and contact type like temperature sensor are used for collecting the data on screen and these data based on a feedback system in which the value of data from the various sensor has a pre-defined set value if on crossing the set value there is an alarm signal and the whole system is IoT based, So the information is online and can easily judge the real condition of oil. Based on the earlier chapter analysis and theoretical framework, the experiment has been performed for monitoring the real conditioning of engine oil and the required result obtained after analysis of the various engine oil.

\section{EXPERIMENTAL SYSTEM ANALYSIS AND DISCUSSION}

In this, the experiment a model made consists of all hardware and software systems and sensor data from various sensors that are implemented in this work send to the cloud through the IoT network and data visualized on the ThingSpeak platform and then analyzed. The flow chart for demonstrating the IoT based sensor data analyses is described as following.

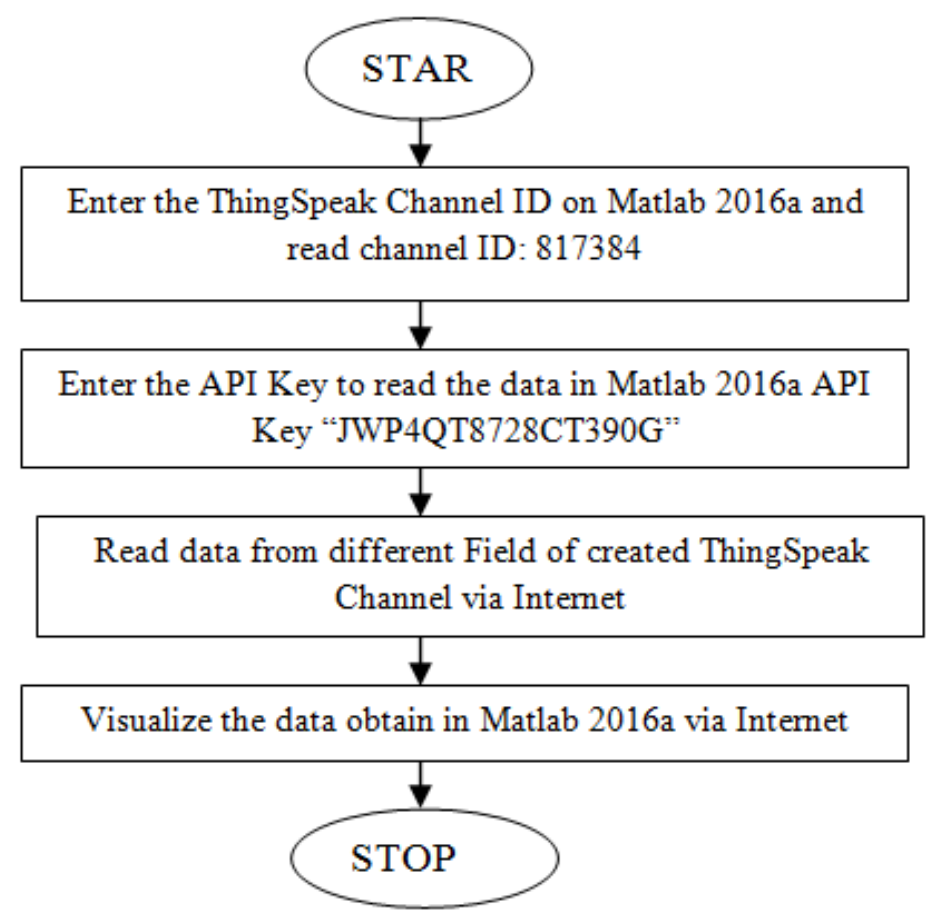

Flow Chart 2: Matlab 2016 A Based Process Flow Chart for Demonstrating the IoT Based Sensor Data Analysis. 
The Flow chart shown above is the data analysis on Matlab R2016a, Once the data get visualized in the ThingSpeak platform then the next step is analyzing the sensed data in Matlab R2016a and for this, we need to have a ThingSpeak supporting toolbox that facilitates to port the sensed data from the ThingSpeak cloud and after installing the toolbox then we need to code using Matlab such that it can successfully get the data from the cloud and we use a channel ID and API key to help for reading and collecting the data from the cloud. Fig 4.highlights the unique ThingSpeak channel ID and Read API key which is used in this project.

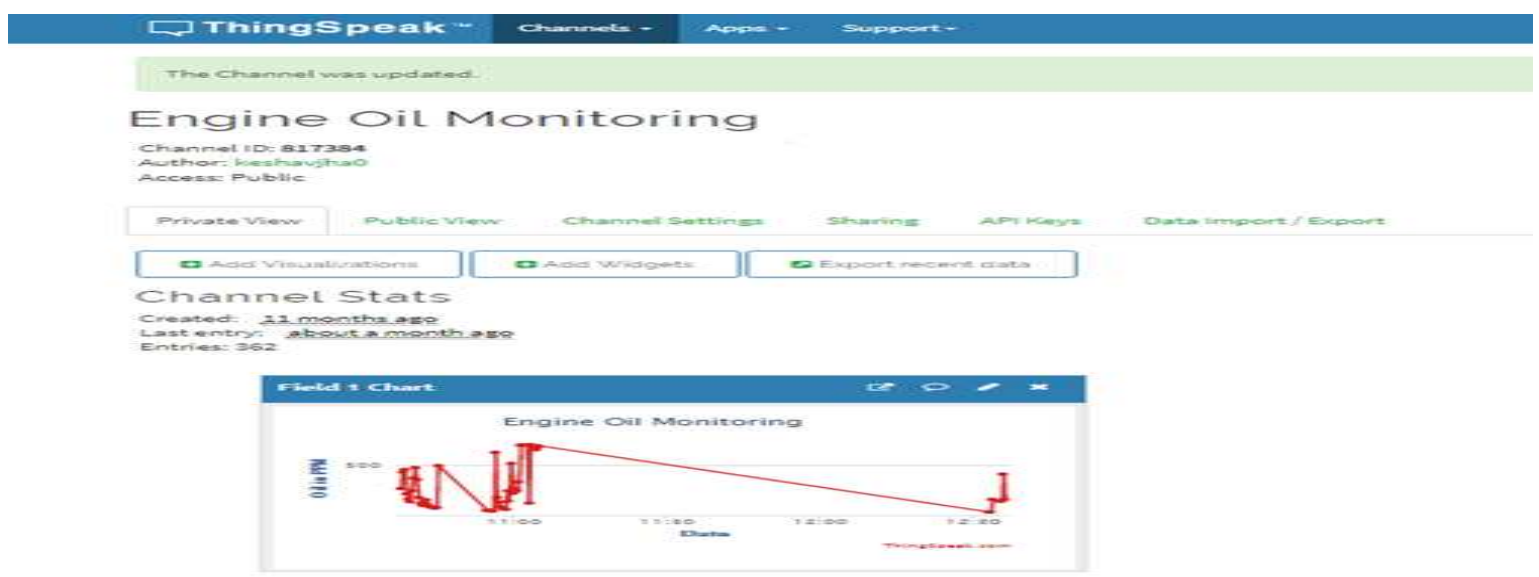

Figure 4: ThingSpeak Channel.

\section{Data obtain on ThingSpeak a IoT Platform}

The program store in the "C" code is used to store this data. This data can be utilized to find out the real-time monitoring of Engine oil or to detect the health of engine oil. In fig 5.5 the uploaded data on ThingSpeak is shown by a graph taken during the testing of engine oil. Once the power from the battery is on then the engine oil flows through a transparent pipe through the LED Sensor and the graph obtains and the indicator buzzer is used if the value reached above 500 it sounds to change the oil, this data is based on the practical experiment-based model. The temperature sensor is used to find the realtime temperature of the engine oil.
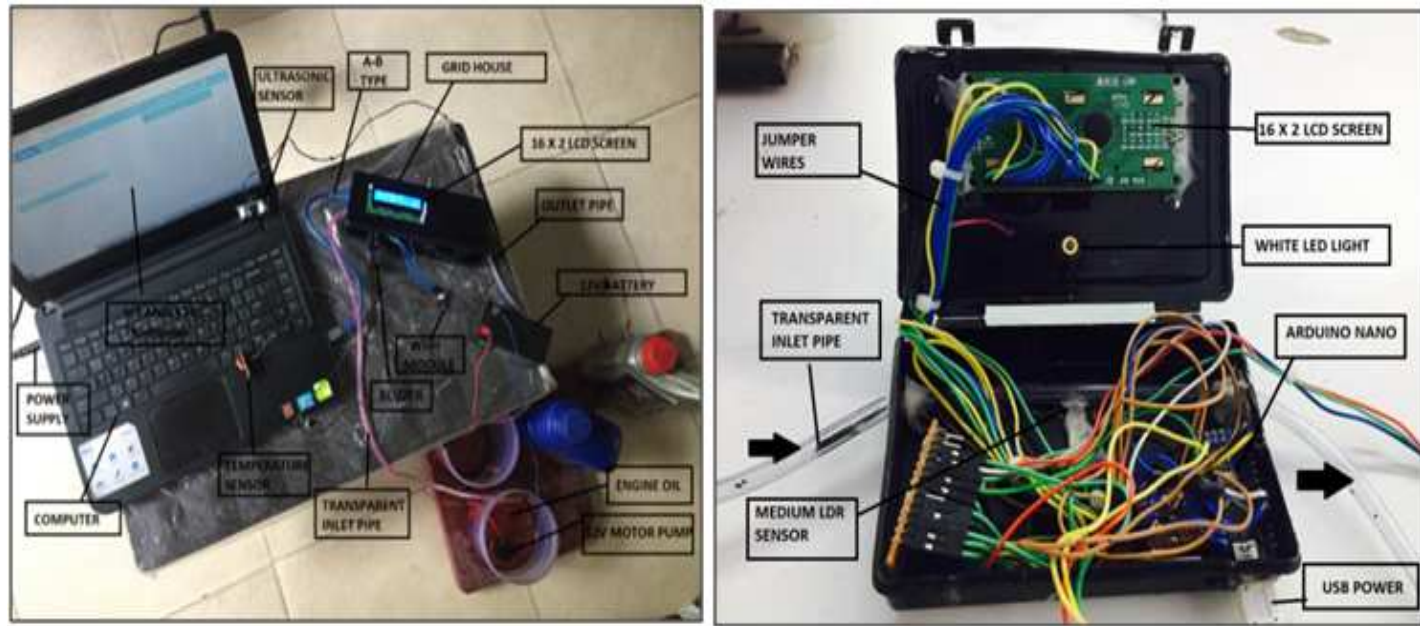

Figure 5: Develop OHM System.

Various steps to analyze the data are:

Step 1: Enter Channel ID number \& API key with the Matlab Syntax so to read the Channel ID \& API Key: 
- $\quad$ ReadChannelID $=817384$

- $\quad$ ReadAPIKey=JWP4QT8728CT390G

Step 2: Run the Matlab code \& the code that starts to read the channel ID \& API key and the various sensed data in the Matlab is been ported to the Matlab R2016a is a graphical plot that can be discussed in the following results and the section.
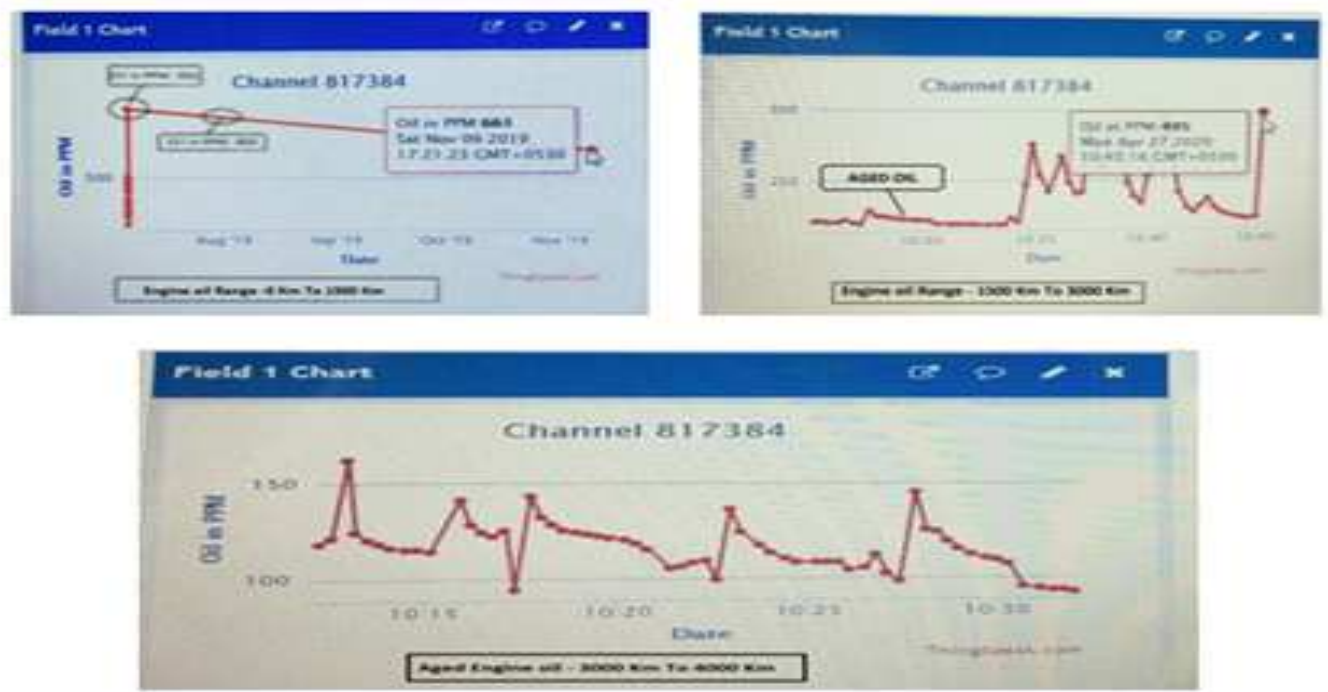

Figure 6: Engine Oil Conditioning (in PPM) Display in Different Time.

\section{Thing Speak IoT Platform}

ThingSpeak platform: This is an IoT analytic platform service that cans you views and analyzes live data in the cloud and also gives you the ability to execute MATLAB Code. The Arduino based Programs for monitoring engine oil in PPM (LED LDR Arduino program, Temperature, ultrasonic sensor) are listed below.

Liquid Crystallcd $(7,8,9,10,11,12)$

String apikey = "JWP4QT8728CT390G"

Software serial ser $(5,6) / /$ RX, TX

Pinmode (4, output):

Digital Wright(4,low);

lcd.begin(16,2);

In the above section use of components with its images are described we also use some of the electronic devices likewise Voltage Regulator (AMS1117), Computer, Tactile Switch A-B Type, Wi-Fi (ESP 8266), Jumper Wire, White, Oil Pipe, LED Buzzer, Battery, Washer Pump (12V) and 2 small buckets. The Block diagram of the Oil Heath Monitoring system with the use of all these components is listed in Fig. 7. 


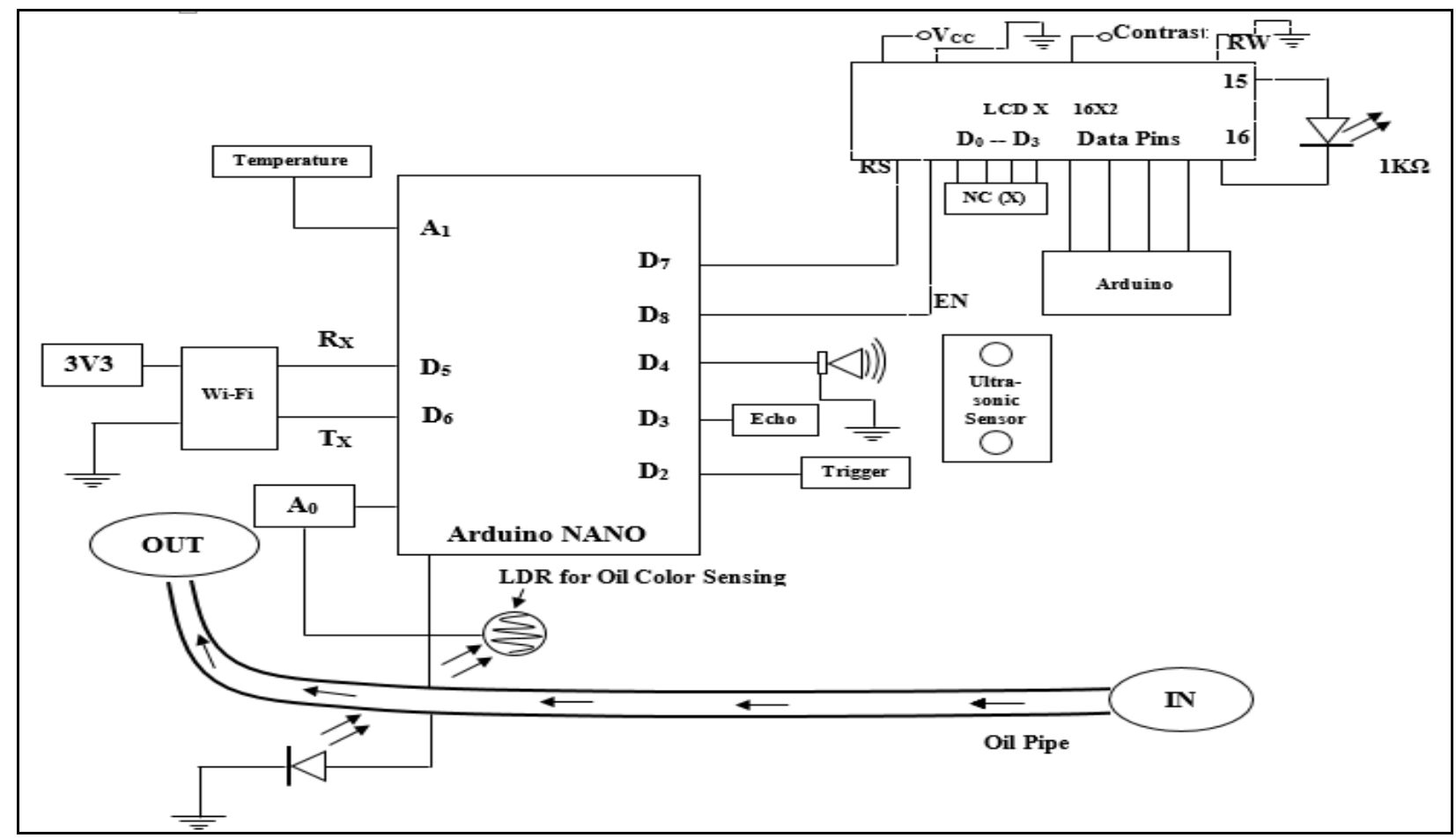

Figure 7: Block Diagram of Oil Heath Monitoring System.

The experimental results from this proposed OHM System using IoT based network are considered and the result with the efficiency of this proposed OHM system is obtained by taking two different scenarios, named as:

- Based on the distance travel, temperature, and level of engine oil first, we consider Motul 10W50 Synthetic twowheeler Honda active (1L), the experiment based on the model to check the quality of engine oil in Parts per million (ppm). For this, we take samples from various kilometers driven from 0 (fresh) to $3300 \mathrm{KM}$.

Table 1: OHM System Result Tested for Scooter Engine Oil-Honda Activa 125(10W-50 4T Synthetic)

\begin{tabular}{|c|c|c|c|c|c|}
\hline $\begin{array}{c}\text { Distance } \\
\text { Average } \\
(\mathbf{K M})\end{array}$ & $\begin{array}{c}\text { Oil Quality } \\
\text { in (PPM) }\end{array}$ & $\begin{array}{c}\text { Temperature } \\
\left({ }^{\mathbf{O}} \mathbf{C}\right)\end{array}$ & $\begin{array}{c}\text { Oil Level } \\
(\mathbf{m m})\end{array}$ & Condition of Oil & $\begin{array}{c}\text { Color } \\
\text { Indication }\end{array}$ \\
\hline 0 & 930 & 28 & 47 & Good & Green \\
\hline 100 & 878 & 27 & 46 & Good & Green \\
\hline 500 & 816 & 28 & 43 & Good & Green \\
\hline 900 & 750 & 26 & 41 & Good & Green \\
\hline 1300 & 650 & 27 & 38 & Moderate & Yellow \\
\hline 1700 & 540 & 27 & 36 & Moderate & Yellow \\
\hline 2100 & 416 & 26 & 34 & Moderate & Yellow \\
\hline 2700 & 370 & 28 & 33 & Degraded & Red \\
\hline 3000 & 300 & 29 & 31 & Degraded & Red \\
\hline 3300 & 180 & 30 & 30 & Degraded & Red \\
\hline
\end{tabular}

- The $2^{\text {nd }}$ scenario of our model-based experiment for the developed OHM system for checking the lubricating engine oil condition which is based on the distance, oil level, and temperature for two-wheeler Yamaha Alpha Scooter Motul 5W 40 Synthetic oil. The result obtains by taking various samples one by one for this scenario that is fully experimental and briefly described the whole result in the tabular form. We take distance range from 0 $\mathrm{KM}$ (fresh) to $3500 \mathrm{KM}$ for checking the condition of engine oil. 
Table 2: OHM System Result Tested for Scooter Engine Yamaha Alpha (5W 40 Synthetic oil)

\begin{tabular}{|c|c|c|c|c|c|}
\hline $\begin{array}{c}\text { Distance } \\
(\mathbf{K M})\end{array}$ & $\begin{array}{c}\text { Oil Quality } \\
\text { in (PPM) }\end{array}$ & $\begin{array}{c}\text { Temperature } \\
(\mathbf{} \mathbf{0})\end{array}$ & $\begin{array}{c}\text { Oil Level } \\
(\mathbf{m m})\end{array}$ & Condition of oil & $\begin{array}{c}\text { Color } \\
\text { Indication }\end{array}$ \\
\hline 0 & 921 & 32 & 48 & Good & Green \\
\hline 92 & 840 & 34 & 46 & Good & Green \\
\hline 467 & 812 & 33 & 45 & Good & Green \\
\hline 886 & 762 & 35 & 41 & Good & Green \\
\hline 1295 & 632 & 31 & 37 & Moderate & Yellow \\
\hline 1641 & 531 & 33 & 35 & Moderate & Yellow \\
\hline 1992 & 408 & 36 & 34 & Moderate & Yellow \\
\hline 2602 & 362 & 34 & 33 & Degraded & Red \\
\hline 3014 & 294 & 31 & 31 & Degraded & Red \\
\hline 3425 & 162 & 38 & 30 & Degraded & Red \\
\hline
\end{tabular}

Based on the above experimental result, which obtained from both scenarios the color indication obtains on screen through the Bluetooth connectivity on the mobile and alert signal when it crosses the limit.

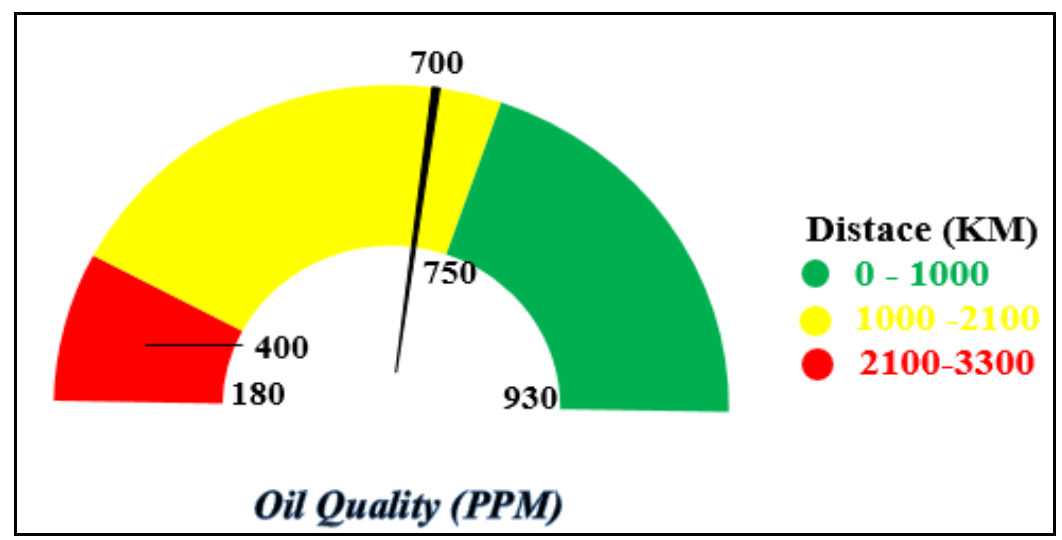

Figure 8: Indicator (Oil Quality in PPM).

Now, from the various sample of oil the experimental analysis based proposed OHM system considered for both quality and quantitative wise analysis, we observed the condition and quantity of lubricating engine oil in both scooters with different synthetic engine oil indicated in terms of color as well as in good, moderate and degraded conditions. So for getting the better result of quantification we use three sensors based OHM system is developed for increasing the overall efficiency of the system.

\section{CONCLUSION AND FUTURE WORK}

The technique in this paper based on the design and implement of an automated engine oil monitoring system in India is done by a conventional manner which is economically more superior and imprecise resulting The above analysis results show that the working model device can be made that can be used for cost-effective and very much reliable method for detecting the oil impurities and depth of oil in the sump. It can also able to send the calculated measured value using the cloud network used and can be displayed on the various screen or mobile apps. The various Instrument or sensor used is working properly. The data can be remotely accessed and the output resolution of the instrument used is a satisfactory level. It is also useful for statistical analysis. This working based model can be used for different grades of oil either engine oil, transformer oil, crude oil, vegetable oil, and other petroleum oil. 


\section{REFERENCES}

1. Shinde, Harish, and Anand Bewoor. "Analyzing the relationship between the deterioration of engine oil in terms of change in viscosity, conductivity and transmittance." In 2017 International Conference on Advances in Mechanical, Industrial, Automation and Management Systems, pp. 36-41. IEEE, 2017.

2. K. Azevedo and D. B. Olsen, "Engine oil degradation analysis of construction equipment in Latin America," J. Qual. Maint. Eng., 2019.

3. Chaudhary, Sumit, Ramesh Chandra Singh, and Rajiv Chaudhary. "An experimental investigation of the impact of nanoparticles on the tribological properties of 15 w40 lubricating oil." vol 8: 185-194.International Journal of Mechanical and Production Engineering Research and Development (IJMPERD) 8. 5, Oct 2018, 185-194

4. T. Holland, A. Abdul-Munaim, D. Watson, and P. Sivakumar, "Influence of Sample Mixing Techniques on Engine Oil Contamination Analysis by Infrared Spectroscopy,” Lubricants, vol. 7, no. 1, p. 4, 2019.

5. Sunrom, “Light Dependent Resistor -LDR,” p. 4pages, 2008.

6. A J. Zhu, D. He, E. Bechhoefer, "Survey of lubrication oil condition monitoring, diagnostics, and prognostics techniques and systems", in Journal of chemical science and technology, July 2013, Vol.2 Iss 3,pp.100-115.

7. Baba, M., C. Tumba, and A. Issa. "Formulation and Performance Assessment of Fixed Oils Based Cutting Fluids in Machining Operation." Int. J. Mech. Eng 7.6 (2018): 11-22.

8. Sejkorová, Marie, and Josef Glos. "Analysis of degradation of motor oils used in Zetor tractors", Acta Universitatis Agriculturae Et Silviculturae Mendelianae Brunensis, vol. 65, no. 1, pp.179-187, 2017.

9. Naik, R. T., and C. Nilesh. "Emission characteristic of a high speed diesel engine." International Journal of Mechanical Engineering, 5, 2936 (2016).

10. B. Jakoby, M. Scherer, M. Buskies, H. Eisenschmid, “An automotive engine oil viscosity sensor”, IEEE Sensors Journal, vol. 3, No. 5, oct. 2003, pp. 562-568 Shinde, Harish, and AnandBewoor. "Analyzing the relationship between the deterioration of engine oil in terms of change in viscosity, conductivity and transmittance." In 2017 International Conference on Advances in Mechanical, Industrial, Automation and Management Systems, pp. 36-41. IEEE, 2017.

11. KalyaniMandekar , PurvaApte, KetkiChaudhari, Minza Ansari, “Iot Based Transformer Parameter Monitoring”, International Journal of Electrical and Electronics Engineer, vol. 9, no. 1, pp. 359-364, 2017

12. Deepak Koranga, "IoT based Condition Monitoring System”, Master's Thesis, Czech Technical University, Dept of Cybernetics, 2017.

13. Alavala, Chennakesava R. "FEM analysis of single point incremental forming process and validation with grid-based experimental deformation analysis." International Journal of Mechanical Engineering 5.5 (2016): 1-6.

14. Agoston, A., Ötsch, C. and Jakoby, B, "Viscosity sensors for engine oil condition monitoring-Application and interpretation of results", Sensors and Actuators A: Physical, vol. 121, no. 2, pp.327-332, Elsevier, 2005.

15. Xprt environmental, “Oil Sampling”, 2017. [Online].Available:https://www.environmental-expert.com/articles/oil-samplingbest-practices-part-2-689553 [Last Accessed: 7 February, 2019].

16. Soleimani, Mostafa, et al. "Base oil oxidation detection using novel chemical sensors and impedance spectroscopy measurements." Sensors and Actuators B: Chemical, vol. 199, pp. 247-258, Elsevier, 2014 
17. Yimin Moa, JunpingWangb *, Jun Wangc, TuoDongd and WenjunZhoue, "Experimental Research on the Impact of Lubricating Oils on Engine Friction and Vehicle Fuel Economy”, In 3rd International Conference on Material, Mechanical and Manufacturing Engineering, pp. 1607-1612, 2015.Soleimani, Mostafa, et al. "Base oil oxidation detection using novel chemical sensors and impedance spectroscopy measurements." Sensors and Actuators B: Chemical, vol. 199, pp. 247-258, Elsevier, 2014.

18. T. Muthamilselvan et al., "We are IntechOpen, the world's leading publisher of Open Access books Built by scientists , for scientists TOP 1 \% Control of a Proportional Hydraulic System,” Intech open, vol. 54, no. June, pp. 713-727, 2016.

19. S. Feng, B. Fan, J. Mao, Y. Xie, and Y. Che, “An oil monitoring method of wear evaluation for engine hot tests," Int. J. Adv. Manuf. Technol., vol. 94, no. 9-12, pp. 3199-3207, 2016.

20. Sunrom, “Light Dependent Resistor -LDR,” p. 4pages, 2008

21. R. Khan, S. U. Khan, R. Zaheer, and S. Khan, "Future internet: The internet of things architecture, possible applications and key challenges," Proc. - 10th Int. Conf. Front. Inf. Technol. FIT 2012, pp. 257-260, 2012.

22. S. M. Azzam et al., "Characterization of essential oils from Myrtaceae species using ATR-IR vibrational spectroscopy coupled to chemometrics," Ind. Crops Prod., vol. 124, no. February, pp. 870-877, 2018.

23. Perić, S., B. Nedić, and A. Grkić. "Applicative Monitoring of Vehicles Engine Oil." Tribology in industry, vol. 36, no. 3, 2014.

24. Besser, C., Dörr, N., Novotny-Farkas, F., Varmuza, K. and Allmaier, G, "Comparison of engine oil degradation observed in laboratory alteration and in the engine by chemometric data evaluation”, Tribology International, vol.65, pp.37-47, Elsevier, 2013

25. Siahaan, Andysah Putera Utama \& Silitonga, Nogar \& Iqbal, Muhammad \& Lubis, Solly \& Fitriani, Wirda \& Ramadhan, Zuhri \& Tharo, Zuraidah \& Rusiadi, Rusiadi \& Hidayat, Rahmat \& AzwarHasibuan, Hasrul \& Nasution, Muhammad \& Ikhwan, Ali \& Azhar, Zulfi, “Arduino Uno-based water turbidity meter using LDR and LED sensors,” International Journal of Engineering and Technology, vol. 7, no. 4, pp. 2113-2117, 2018.

26. L. Hong and K. Sengupta, "Fully integrated optical spectrometer with 500-to-830nm range in 65nm CMOS," Dig. Tech. Pap. - IEEE Int. Solid-State Circuits Conf., vol. 60, pp. 462-463, 2017

27. Rajakumar, G., Kumar, T. A., Samuel, T. A., \& Kumaran, E. M, “IoT Based Milk Monitoring System For Detection Of Milk Adulteration”, International Journal of Pure and Applied Mathematics, vol. 118, no. 9, pp. 21-32, 2018. 